\title{
A PEGADA ECOLÓGICA DO CONSUMO DE ÁGUA DO MUNICÍPIO DE CAICÓ/RN
}

\author{
Milenna Dantas Lacava de Almeida \\ Núcleo de Estudos do Semiárido - NESA, IFRN, Natal - Central, PIBITI/CNPq, Graduanda \\ do curso de Tecnologia em Gestão Ambiental, milennadantasl@yahoo.com.br \\ Carlos Antonio Lira Felipe Neto \\ Núcleo de Estudos do Semiárido - NESA, IFRN, Natal - Central, PIBITI/CNPq, Graduando \\ do curso de Tecnologia em Gestão Ambiental, calfneto@ hotmail.com \\ Leci Martins Reis \\ Núcleo de Estudos do Semiárido (NESA), IFRN, Campus Natal-central, Graduação em \\ Geografia pela UFRR (1994), Mestrado em Desenvolvimento e Meio Ambiente pela UFPB \\ (2001), Doutoranda em Recursos Naturais do DINTER-UFCG/IFRN (2010), professora \\ orientadora, leci.reis@ifrn.edu.br \\ Valdenildo Pedro da Silva \\ Núcleo de Estudos do Semiárido - NESA, IFRN, Natal - Central, Graduação em Licenciatura \\ em Geografia pela UFRN (1988), Mestrado em Geografia pela UFPB (1999), Doutorado em \\ Geografia pela UFRJ (2005), professor colaborador, valdenildo@cefetrn.br
}

\section{RESUMO}

A depleção dos recursos naturais acometidos pelas atividades antrópicas continuam ocorrendo de maneira desenfreada, por mais que as pesquisas e discussões sobre o tema sustentabilidade tenham, ao longo dos últimos anos, se popularizado. Mas, o homem ainda persiste em deixar suas pegadas. A Pegada Ecológica (PE), proposta por Ress e Wackernagel (1962) e, mais a frente, adaptada por Dias (2006) e Bellen (2008), surge como um instrumento de avaliação da sustentabilidade de um determinado local a partir dos cálculos de consumo de itens individualizados. A mudança dos padrões climáticos, a semi-aridez e as implicações decorrentes da agricultura familiar, são um alerta da exaustão do atual modelo de produção e consumo adotados pelas pessoas de uma dada área territorial ou de um município. Percebendo a necessidade de mensurar essa exaustão, o estudo em tela objetiva calcular a pegada ecológica do consumo de água do município de Caicó/RN, por entender que a disponibilidade hídrica da região é um dos principais itens causadores da insustentabilidade local. Para isso, utiliza-se uma metodologia fundamentada, principalmente, por Parente (2007) e Chambers et al. (2000), a partir de dados secundários fornecidos pelo Instituto Brasileiro de Geografia e Estatística (IBGE) e a Companhia de Águas e Esgotos do Rio Grande do Norte (CAERN), em que se calculou a Pegada Ecológica com base no consumo de água das pessoas do município de Caicó/RN. Dessa forma, conclui-se que apenas para o consumo de água são necessários 966,835715 hectares globais de terra para suportar os fluxos de entrada e saída da região. Contudo, trata-se de um sinal de alerta, propondo-se uma urgente conscientização popular, a partir de práticas de educação ambiental no município e de ações efetivas do poder público local.

PALAVRAS-CHAVE: Pegada Ecológica, Sustentabilidade, Caicó, Disponibilidade Hídrica. 


\title{
THE ECOLOGICAL FOOTPRINT OF WATER CONSUMPTION OF THE MUNICIPALITY OF CAICO/RN
}

\begin{abstract}
The depletion of natural resources affected by anthropogenic activities are still occurring of unbridled way, by more than the research and discussions on the theme sustainability has, over the last few years, if popularized. But, the man still persists in leave his footsteps. The Ecological Footprint (PE), proposed by Ress and Wackernagel (1962) and, more than the front, adapted by Dias (2006) and Bellen (2008), emerges as an instrument for assessing the sustainability of a given place from the calculations of consumption of items individualized. A change of climate patterns, the semi-aridity and the implications of family agriculture, are a warning of exhaustion of the current model of production and consumption adopted by persons of a given area or a municipality. Perceiving the need to measure that exhaustion, the study objective screens calculate the ecological footprint of water consumption of the municipality of Caicó/RN, as the availability of water of the region is one of the main items causing the unsustainability place. For this purpose, uses-if a methodology based, mainly, by relation Parente (2007) and Chambers et al. (2000), from secondary data supplied by the Brazilian Institute of Geography (IBGE) and Statistics and the Company of Water and Sewerage of Rio Grande do Norte (CAERN), in which it calculated the Ecological Footprint on the basis of water consumption of people in the municipality of Caicó/RN. Thus, it is concluded only for the consumption of water are needed global 966.835715 hectares of land to bear the flows into and exit of the region. However, this is a warning signal, proposing an urgent awareness popular, from practices of environmental education in the municipality and effective actions of local.
\end{abstract}

KEY-WORDS: Ecological Footprint, Sustainability, Caicó, Availability of Water. 


\section{A PEGADA ECOLÓgICA DO CONSUMO DE ÁGUA DO MUNICÍPIO DE CAICÓ/RN}

\section{INTRODUÇÃO}

A humanidade contemporânea vive um período de crise entre o crescimento e a degradação ambiental. Atesta-se a cada dia a necessidade de uma reflexão sistemática sobre a influência da sociedade em detrimento do ambiente. Assim, devido à grave situação acometida nas diversas escalas, globais e locais, e a fim de mensurar a ausência de equilíbrio ecológico entre homem e meio ambiente, são necessários parâmetros ou indicadores obtidos por metodologias que contemplam a discussão e avalia os índices de sustentabilidade.

Não sendo diferente, na microrregião ocidental do Estado do Rio Grande do Norte (RN), a devastação dos recursos naturais por meio dos novos e velhos processos econômicos, vem preocupando a população caicoense. O agravante é devido a região se caracterizar por ser uma área semiárida, com forte insolação, altas temperaturas, e regime de chuvas escasso e irregular, desenvolvendo assim, um cenário propício a desertificação.

Entende-se a necessidade, para tanto, de um instrumento de medida que delimite os fluxos de entrada e saída de recursos naturais de um determinado local, a fim de saber o grau de sustentabilidade deste. A idéia base é a de que cada indivíduo, processo, atividade e região proporcionam um impacto terrestre através do uso indiscriminado de recursos, geração de resíduos e uso de serviços fornecidos pela natureza, e por isso, quantifica-se em hectares a quantidade necessária a suportar esses fluxos de energia e massa.

A problemática gira em torno de que já por volta de 1986, a pegada humana total atingiu o ponto limítrofe da capacidade ecológica da Terra. Depois desse período, esse Planeta não tem sido mais suficiente para suportar as atividades antrópicas. Hails et al. (2006, apud JARRA, 2007) ainda afirmam que na pegada para o ano de 2003 foi estimada a necessidade de 1,25 planetas para suportar as atividades da época e obter a sustentabilidade tão solicitada. De modo que cada região tem sua influência, o município de Caicó, situado na microrregião do Seridó Ocidental, não se distingue dos demais, apresentando seu índice de sustentabilidade desconhecido.

Assim, questiona-se: qual a pegada ecológica referente ao consumo de água do município de Caicó, palco da desertificação norte-rio-grandense? Buscam-se números atuais e específicos para a realidade da região para que se possa estimar o quão a população caicoense necessita de área em hectares, para o abastecimento da água sem que haja prejuízos para o ecossistema local.

A fim de responder tais indagações, o trabalho objetiva calcular a pegada ecológica do consumo de água do município de Caicó/RN. Preocupando-se em destacar o grau de consumo de água da população.

A escolha do tema foi impulsionada pela ausência de estudos atuais específicos da sustentabilidade sobre a microrregião do Seridó Ocidental e principalmente o município em questão. Ainda, foi observada a necessidade de mensurar os processos de produção, uso e ocupação dos recursos naturais na tentativa de resgatar os processos históricos estabelecidos, uma vez que a região oferece grandes chances de se tornar um deserto do semiárido 
(ARAÚJO, ALMEIDA, GUERRA, 2005). Compreende-se, portanto, a importância de se retardar esse processo e, mais à frente, restituí-lo.

Além disso, o estudo em pauta diz respeito a uma parte do projeto A ECOLOGICAL FOOTPRINT (PEGADA ECOLÓGICA) COMO INSTRUMENTO DE AVALIAÇÃO DA SUSTENTABILIDADE AMBIENTAL NA MICRORREGIÃO DO SERIDÓ NORTE-RIOGRANDENSE que fora aprovado pelo CNPq por meio do Programa Institucional de Bolsas de Iniciação Científica em Desenvolvimento Tecnológico e Inovação (PIBITI), iniciado em agosto de 2010 e com previsão de doze meses para seu término.

A consecução dessas questões deu-se através de procedimentos de cunho qualitativo e quantitativo, por meio de levantamentos bibliográficos, teses, dissertações e análises de cálculos para a obtenção da pegada ecológica. A pesquisa se baseou pela obtenção de dados secundários do Instituto Brasileiro de Geografia e Estatísticas (IBGE) e da Companhia de Águas e Esgotos do Rio Grande do Norte (CAERN) e nos cálculos propostos por Parente (2007) e Chambers et al. (2000), principalmente. Portanto, a pesquisa tem caráter exploratório, descritivo, bibliográfico e documental (GIL,1999), devido as exigências do próprio método.

Desse modo, além da seção introdutória, o artigo se estrutura em mais quatro seções. A segunda seção trata-se do aporte teórico, obtendo-se conceitos da Pegada Ecológica (PE) e caracterizações do objeto de estudo. Em consequiência, na terceira seção, é abordado os procedimentos metodológicos utilizados. A apresentação dos resultados e sua análise são propostos na quarta seção e, por último, na quinta seção, observa-se as considerações finais da pesquisa.

\section{APORTE TEÓRICO}

Nesta seção de aporte teórico serão expostos os principais autores que deram embasamento a consecução desta pesquisa, os quais foram responsáveis por definir o método da Pegada Ecológica (PE) e aplica-la no município em questão, bem como da variável água.

\section{PEGADA ECOLÓGICA}

O socioecossistema urbano e rural vem historicamente sendo degradado e sofrendo profundas agressões e alterações em sua biosfera. O modelo sustentável, bastante debatido, é a única solução para darmos continuidade ao crescimento populacional e econômico de forma duradora.

O ritmo de crescimento acelerado do século XX sustentou um colapso ecológico continuado. Foi devido à preocupação de transformar estudos referentes à degradação ambiental em números que alguns pesquisadores desenvolveram os indicadores de sustentabilidade. Uma das ferramentas propostas para essa quantificação, em meados dos anos de 1960, foi o do ecological footpring method, traduzido como o método da pegada ecológica, como prenunciaram Ress e Wackernagel (1962).

Esse método surge como instrumento de avaliação ambiental de forma clara, integrada e simples, sendo capaz de diagnosticar os resultados das atividades humanas desenvolvidas no ecossistema e os custos ocasionados pela apropriação de áreas naturais. (DIAS, 2006). Objetiva-se a partir desse indicador, estimar o quanto em números por hectares, se faz 
necessário para sustentar uma dada população, o quanto de recursos naturais são necessários para suprir o consumo desta.

Desse modo, a avaliação consiste num cálculo da área necessária de terra suficiente para manter o sistema de produção ativo e receber os dejetos por ele provocados. O método da Pegada Ecológica (PE) baseia-se no conceito de capacidade de carga, ou seja, na máxima população que pode ser suportada pelo sistema. Refere-se, assim, a carga máxima que pode ser imposta ao meio ambiente pela sociedade. Avalia-se, a área de terra necessária para assegurar a sobrevivência se uma determinada população (BELLEN, 2006).

Assim sendo, o método não procura definir a população adequada para determinada região e sim o contrário, calcular a área que determinada população necessita através da contabilidade dos fluxos de energia e matéria que entram e saem do sistema. Como bem expõe Ress (1990, apud DIAS, 2006), o ser humano continua um dependente obrigatório dos serviços dos ecossistemas e, com o crescimento gradativo da população e do consumo, a área produtiva em seu estoque identifica declínio.

De fato, as análises já feitas em regiões do mundo e do Brasil, expõe o drama da insustentabilidade e salienta a necessidade de ajustes. Para tanto, afirma Dias (2006, p.186):

\begin{abstract}
Se a população mundial continuar a crescer e chegar aos 10 bilhões de habitantes em 2040, como previsto, cada ser humano terá apenas 0,9 ha de terra ecoprodutiva (assumindo que não haja mais degradação do solo). Viver sob tais condições pode significar absoluta inviabilidade ou desmonte da forma atual de organização e estrutura da sociedade humana.
\end{abstract}

Em virtude disso, o desenvolvimento sustentável vem a se tornar mais do que uma simples reforma, passando a ser uma efetiva transformação social. Além do que, é relevante abordar que o cálculo fundamenta-se em dados positivos. Como bem ilustra o autor, estabelecem-se dados com base na suposição de que a agroindústria utiliza métodos sustentáveis, melhores tecnologias e produtividades elevadas, o que, como sabemos, não corresponde com a realidade.

Para tanto, o cálculo da pegada ecológica identifica que para cada item de matéria ou energia consumida, há uma certa área de terra necessária para fornecer tais fluxos. $\mathrm{O}$ balanço proposto por Ress e Wackernagel (1962), atende aos requisitos gerais de sua fundamentação. Assim, muitos autores, a fim de especificar o cálculo para sua variável em sua localidade, foram produzindo ampliações dessa metodologia original. Autores como Genebaldo Dias e Van Bellen merecem destaque quanto à implantação de metodologias bastante específicas utilizando o maior número de variáveis possíveis para o calculo de sua região.

A utilização das variáveis dar-se-á devido à busca por estatísticas regionais, dados secundários, de forma mais específica, sofisticada e realista, por meio de cinco características entendidas pelos pesquisadores como as mais indicadas: alimentação, transporte, habitação, bens de consumo e serviços, podendo ser substituídas com vista na necessidade da região. Dessa forma, calcula-se a pegada de cada um desses itens para se ter noção do grau de impacto de cada um destes em relação à pegada total.

Uma vez que a pegada ecológica deve ser avaliada em hectares globais, há uma melhor sistematização e transferência desses dados para todo o mundo. Qualidade pertinente já que o acesso a essas ferramentas podem contribuir com a comparação e efetiva execução de planos de sustentabilidade adotados. 
Não obstante a PE ser um método avaliado como conciso e bem fundamentado, como todos os outros métodos, também esta passível a críticas. Uma destas relata a ausência de relação social existente na avaliação dos indicadores, já que a pegada não é fixa devendo ser alterada de região a região. De fato, a ferramenta aborda apenas os recursos naturais sem se preocupar com a economia e a sociedade (Bossel, 1999 apud BELLEN, 2006).

Uma limitação da pegada ecológica, proposta por Hardi e Barg (1997 apud BELLEN, 2006), diz respeito ao método apresentar dados sistematizados de forma estática. Ou seja, constitui uma ferramenta na qual não pretende fazer extrapolações futuras, utiliza apenas dados já coletados atualmente. Todavia, existem certas questões que são imprescindíveis que sejam analisadas de forma quantitativa e com certeza essa é a melhor forma de avaliação.

O intuito é que através dessa ferramenta de forte procedência a nível mundial, se mensure a produção e o consumo dos recursos naturais essenciais à vida, no intuito de minimizar as perdas e degradações, substituindo as formas de produção por maneiras mais eficazes. Capturar a complexidade do desenvolvimento, sem reduzir a significância de cada um dos componentes do ecossistema, sem atrapalhar economicamente cada região estudada, e sim, torná-la sustentável.

\section{CARACTERIZAÇÃO SOCIOESPACIAL DA ÁREA DE ESTUDO}

Caicó, município brasileiro do Estado do Rio Grande do Norte (RN), antiga Vila do Príncipe, está localizado na Mesorregião Central Potiguar, mais precisamente na Microrregião do Seridó Ocidental na periferia da Serra da Borborema, situado à aproximadamente $280 \mathrm{~km}$ de distância da capital do Estado. Com uma área de $1.229 \mathrm{~km}^{2}$, comportando uma população de 62.727 habitantes (IBGE, 2010), a região apresenta como municípios limítrofes as cidades de: Jucurutú (norte); Florânia, Cruzeta, São José do Seridó, Jardim do Seridó e Ouro Branco (leste); São João do Sabugi (sul) e Serra Negra do Norte, Timbaúba dos Batistas e São Fernando (Oeste), conforme verifica-se na figura 01. 


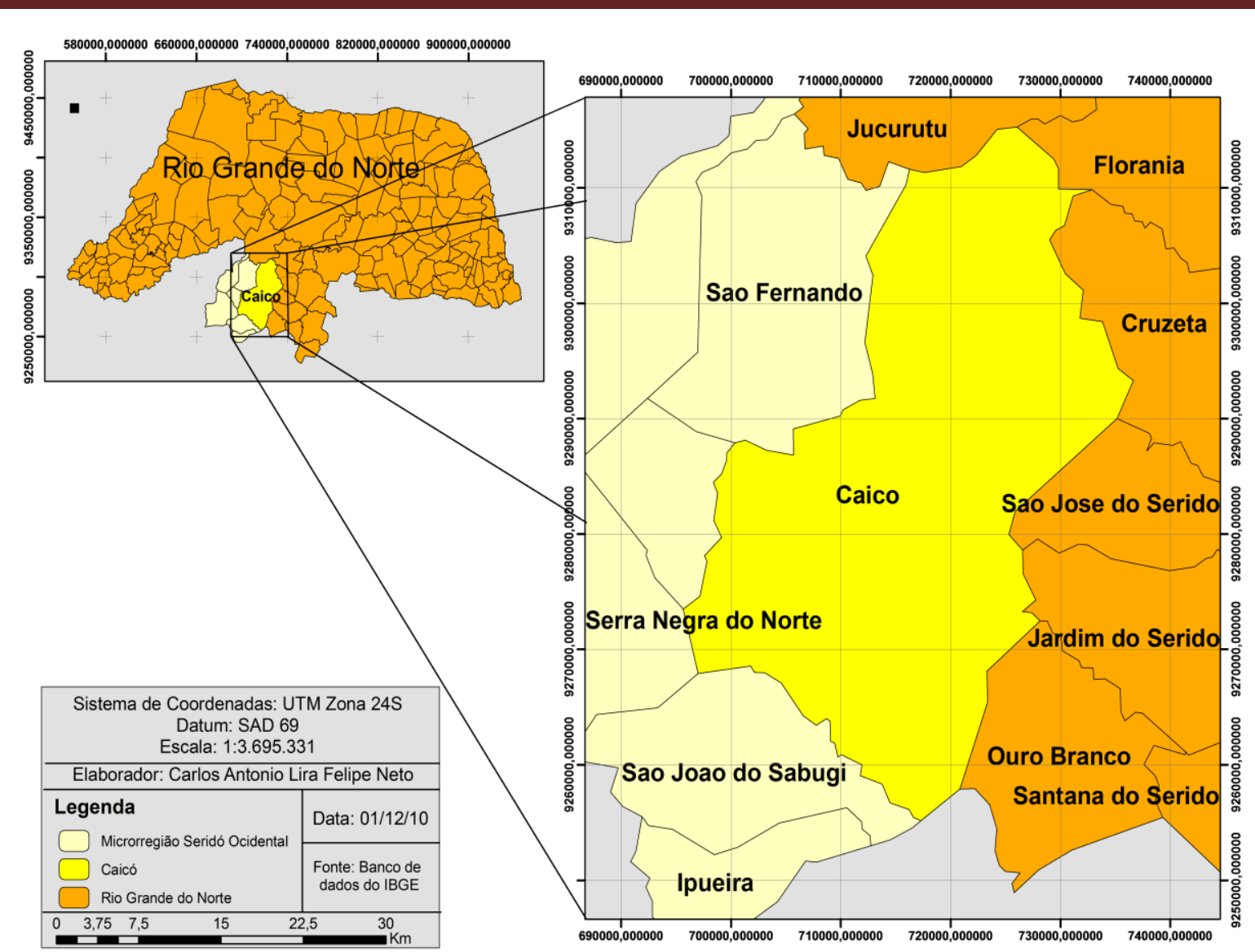

Figura 3 - Mapa mostrando a localização do município de Caicó/ RN.

Entre um dos cinco municípios de maior relevância para o Estado, intitulado popularmente como a Capital do Seridó, Caicó tem, ao longo dos anos, contribuído de forma efetiva para a economia do Seridó. Merecendo destaque a produção de bonés e bordados nacionalmente prestigiados, como também, o turismo festivo com as comemorações do famoso carnaval e da festa de Sant'Ana que impulsionam o comércio regional. Entretanto, a agricultura familiar, a produção de leite, carne de sol e queijo, ainda continuam como sendo o principal sustento da região.

De acordo com o Diagnóstico do Município de Caicó (2005), a vegetação predominante da região é a Caatinga, desenvolvida suportando as intensas irregularidades pluviométricas, resultantes do clima semiárido e do solo pedregoso dominante. Sua temperatura média anual é de $27,4^{\circ} \mathrm{C}$ e suas variáveis pluviométricas variam entre 400 a 600 milímetros.

Desse modo, a caracterização da região dar-se-á fundamentalmente pela disponibilidade de água e a quantidade de chuvas. O clima diferenciado, com predominância de massas de ar instáveis, a alta temperatura média anual e a radiação solar, aliado as intensas alterações feitas para o homem adaptar-se, a grave degradação do solo pelas culturais queimadas e o aumento da evaporação das águas, faz o cenário do município estar inserido na categoria "muito grave" de desertificação (ALVES; MEDEIROS,2005).

Para tanto, a região atende a uma média de 15 (quinze) dos 19 (dezenove) indicadores de desertificação, ocasionados pela forte erosão e seus conseqüentes impactos sobre recursos hídricos. Alves e Medeiros (2005) ainda alegam que os principais fatores são decorrentes das 
atividades pecuárias e a produção agrícola, nas quais geraram o desmatamento e o empobrecimento do solo.

De acordo com a Comissão das Nações Unidas para o Meio Ambiente e Desenvolvimento (CNUMAD) (1992), entende-se por desertificação a degradação da terra nas regiões áridas, semi-áridas e sub-úmidas secas, resultantes de vários fatores, entre eles as variações climáticas e atividades humanas. Assim, muitos autores já afirmam a possibilidade, cada vez mais real, dessa região, situada no Seridó do RN, virar um deserto, estando 41,7\% do Estado afetado.

\section{VARIÁVEL ÁGUA}

A humanidade vem passando por uma explosão de experimentos globais. Mudanças diferentes ocorrem simultaneamente, grandes quantidades de gases têm sido emitidas, o que conjuntamente as variações nas temperaturas naturais e as aceleradas atividades antrópicas, configuram o status de urgência imposto a todos.

Assim, surge a necessidade de não mais se utilizar os indicadores de sustentabilidade de forma genérica. Utilizando o maior número de itens individualizados, obtemos uma detalhada pegada ecológica. Pensando assim, na busca de novas ferramentas analíticas e sintéticas, deve-se encontrar variáveis que estejam intrinsecamente ligadas aos problemas da região escolhida.

E, mesmo com todos os avanços biológicos, químicos e tecnológicos, a água é um fator limitante vital para as espécies que vivem na Terra. A negligência histórica dos seres humanos, os desmatamentos, as condições de clima e solo, justificam, em partes, a ausência de disponibilidade hídrica.

Em verdade, da água existente na Terra, 97,5\% estão nos mares, apenas 2,5\% de água doce. Desses 2,5\%, 68,9\% estão sob a forma de gelo polar, portanto, indisponíveis. Como água potável tem-se $29,9 \%$ do total de água disponível, estando a maioria na forma subterrânea. (APRH). Revela-se, portanto, as situações dramáticas que muitos estão submetidos e entendese a urgência de quantificarmos e qualificarmos as ações humanas utilizando a pegada.

De fato grande parte das alterações globais ocorre de forma indireta, através da intervenção humana, pelo consumo demasiado da água. Na visão de Genebaldo Dias (2006, p.159):

\footnotetext{
A captação, o armazenamento, o tratamento, a distribuição e a manutenção de todo o sistema envolvem investimentos financeiros colossais, acompanhados em sua magnitude de criação e pressão sobre os recursos naturais. Essa pressão vai desde o barramento, com suas influências sobre áreas naturais, [...] até o consumo de combustíveis, eletricidade, produtos químicos para o tratamento [...]. Considerandose que esse processo é comum à maior parte das cidades do mundo, tem-se uma idéia da contribuição que este item acrescenta às alterações ambientais globais.
}

De acordo com O’Meara (1999), as áreas urbanas, que contemplam mais da metade da população mundial, são responsáveis por $80 \%$ das emissões de carbono, $75 \%$ do uso da madeira e $60 \%$ do consumo de água. As cidades ocupam apenas de 1 a $5 \%$ da área do planeta, mas consomem $75 \%$ de seus recursos. Elas podem ser consideradas como "pontos quentes", pois um hectare de uma área metropolitana consome mais de 1000 vezes energia que a mesma área em um ambiente natural. 
Aliado a isso, o problema da água está na desigual distribuição entre as diversas regiões, nas exigências cada vez maiores de consumo, principalmente nos sistemas produtivos. Cerca de $3,3 \%$ da disponibilidade hídrica do Brasil está na região do Nordeste, mais de $60 \%$ a menos do que na região Norte, conforme dados da Agência Nacional de Águas (2005). No município objeto de estudo, a disponibilidade é de extrema escassez devido aos índices anteriormente discutidos.

O município de Caicó, objeto do nosso estudo, concentra o período chuvoso nos cinco primeiros meses do ano, apresenta uma evapotranspiração total anual de $577 \mathrm{~mm}$, com variações acentuadas, e um déficit hídrico anual de $409 \mathrm{~mm}$, acentuando-se nos meses de junho a dezembro, segundo dados disponibilizados pela Universidade Federal do Rio Grande do Norte - Campus Caicó. A região se depara com um percentual de, no mínimo, $5 \%$ da população urbana sem acesso a água, uma vez que o principal meio de acesso hídrico oferece um volume médio de $400.500 \mathrm{~m}^{3}$ de água, insuficientes para o consumo da região.

Assim sendo, torna-se imprescindível a obtenção do cálculo da pegada ecológica como forma de indicar os danos sofridos na região e propagar possíveis soluções. Obteremos, portanto, o quanto de área produtiva e água são necessários para manter a população caicoense, representando a apropriação da capacidade de suporte desta.

\section{PROCEDIMENTOS METODOLÓGICOS}

No campo metodológico, a pesquisa, do ponto de vista da sua natureza, classifica-se como pura ou básica. Já no que diz respeito a sua abordagem, apresenta-se de maneira qualitativa e quantitativa, pois o método utilizado busca a coleta de informações e o levantamento de dados numéricos para obtenção do diagnóstico da Pegada Ecológica.

Nesse sentido, vale ressaltar que a sistemática do cálculo da Pegada Ecológica, proposta inicialmente por Wackernagel e Rees (1996), e posteriormente, com contribuições de Bellen (2008), Parente (2007), Dias (2006) e Chambers et al. (2000), contribuiu para quantificar o quanto cada caicoense necessita em hectares para que o abastecimento de água seja oferecido sem que haja perdas para o meio natural.

Para o presente estudo, necessitou-se do levantamento de dados secundários referentes ao ano de 2010, fornecidos pelas seguintes instituições: o Instituto Brasileiro de Geografia e Estatística (IBGE) e a Companhia de Águas e Esgotos do Rio Grande do Norte (CAERN). Trata-se, portanto, de uma pesquisa bibliográfica, a qual permitiu uma base teórica das informações e procedimentos da Pegada Ecológica, bem como das exigências do próprio método.

A variável escolhida para a análise da Pegada Ecológica foi a água, visto que o município de estudo se encontra em uma região que carece de mais atenção tanto por parte do governo, quanto do própria população caicoense, por estar localizado em uma região semi-árida, que apresenta baixa pluviosidade, como já exposto.

Diante disso, e de acordo com os procedimentos utilizados por Parente (2007), para a análise dos resultados foi levado em consideração as seguintes etapas e transformações:

a) Etapa 1 - Levantamento da população, conforme dados do IBGE (2010); 
b) Etapa 2 - Consumo total da água, referente ao ano 2010, de acordo com os dados fornecidos pela Companhia de Águas e Esgotos do Rio Grande do Norte (CAERN);

c) Etapa 3 - Levando-se em consideração o conceito de Chambers et al. (2000 apud PARENTE, 2007) de que 01 (um) litro de água é igual a $0,001 \mathrm{~m}^{3}$ e 1 (um) megalitro corresponde a $1.000,00 \mathrm{~m}^{3}$, converte-se o total de água consumido de metros cúbicos para megalitros;

d) Etapa 4 - Obteve-se o resultado total de gás carbônico $\left(\mathrm{CO}_{2}\right)$ emitidos em toneladas, a partir da equivalência proposta por Chambers et al. (2000 apud PARENTE, 2007), baseando-se no tratamento, encanamento e distribuição da água. Desse modo, o consumo de 1 (um) megalitro de água equivalem a emissão de $370 \mathrm{~kg}$ de $\mathrm{CO}_{2}$ para a atmosfera. Assim, $370 \mathrm{~kg}$ de correspondem a 0,37 toneladas;

e) Etapa 5 - Com base no relatório do Painel Intergovernamental sobre Mudanças Climáticas (PNUMA, 2007), uma área de 1 (um) hectare tem capacidade de absorver 1 (uma) tonelada de $\mathrm{CO}_{2}$ emitida. Desse modo, obtém-se a cálculo da Pegada Ecológica da população em hectare. Como a divisão do total de $\mathrm{CO}_{2}$ foi dividida por um, concluíse então que, o resultado da etapa 5 é equivalente ao da etapa anterior (etapa 4);

f) Etapa 6 - A Pegada Ecológica per capita foi obtida em função da divisão entre a Pegada Ecológica da população em hectare (etapa 5) e o número total de habitantes (etapa 1);

g) Etapa 7 - O resultado da Pegada Ecológica global hectare total (gha) foi alcançado através da multiplicação da Pegada Ecológica da população em hectare (etapa 5) pelo fator de equivalência 1,3, referente à produtividade da área de floresta (PARENTE, 2007);

h) Etapa 8 - A Pegada Ecológica global hectare per capita foi calculada efetuando-se a divisão entre a Pegada Ecológica global hectare total (gha) (etapa 7) e o número de habitantes (etapa 1).

A tabela 1 apresenta as etapas, a população, o consumo de água em $\mathrm{m}^{3}$, o consumo de água em megalitro, o total de $\mathrm{CO}_{2}$ emitidos em toneladas, a Pegada Ecológica da população em hectare, a Pegada Ecológica per capita em hectare, a Pagada Ecológica global total em hectare e a Pegada Ecológica global per capita em hectare.

Tabela 1 - Cálculo da Pegada Ecológica referente ao consumo de água do município de caicó

\begin{tabular}{|c|c|c|c|c|c|c|c|c|}
\hline & População & $\begin{array}{c}\text { Consumo } \\
\left(\mathrm{m}^{3}\right)\end{array}$ & $\begin{array}{c}\text { Consumo } \\
(\mathrm{mgl})\end{array}$ & $\begin{array}{c}\text { Total de } \\
\text { CO2 } \\
\text { emitido } \\
(\mathrm{t})\end{array}$ & $\begin{array}{c}\text { PE (ha) } \\
\text { População }\end{array}$ & $\begin{array}{c}\text { PE (ha) Per } \\
\text { capita }\end{array}$ & $\begin{array}{c}\text { PE Total } \\
\text { (gha) }\end{array}$ & $\begin{array}{c}\text { PE Per } \\
\text { capita (gha) }\end{array}$ \\
\hline Etapa & $\mathbf{1}$ & $\mathbf{2}$ & $\mathbf{3}$ & $\mathbf{4}$ & $\mathbf{5}$ & $\mathbf{6}$ & $\mathbf{7}$ & $\mathbf{8}$ \\
\hline $\begin{array}{c}\text { Variável } \\
\text { água }\end{array}$ & $\mathbf{6 2 . 7 2 7}$ & $\mathbf{1 . 9 0 7 . 3 5 0}$ & $\mathbf{1 9 0 7 , 3 5}$ & $\mathbf{7 0 5 , 7 1 9 5}$ & $\mathbf{7 0 5 , 7 1 9 5}$ & $\mathbf{0 , 0 1 1 2 5 0 6 5}$ & $\mathbf{9 6 6 , 8 3 5 7 1 5}$ & $\mathbf{0 , 0 1 5 4 1 3 3 9}$ \\
\hline Total & $\mathbf{6 2 . 7 2 7}$ & $\mathbf{1 . 9 0 7 . 3 5 0}$ & $\mathbf{1 9 0 7 , 3 5}$ & $\mathbf{7 0 5 , 7 1 9 5}$ & $\mathbf{7 0 5 , 7 1 9 5}$ & $\mathbf{0 , 0 1 1 2 5 0 6 5}$ & $\mathbf{9 6 6 , 8 3 5 7 1 5}$ & $\mathbf{0 , 0 1 5 4 1 3 3 9}$ \\
\hline
\end{tabular}

Fonte: IBGE (2010) e CAERN (2010) 


\section{APRESENTAÇÃO DOS RESULTADOS}

Diante dos dados encontrados, pode-se inferir que a Pegada Ecológica total da população caicoense (correspondente a 62.727 habitantes), em hectares globais (gha), referente ao consumo de água, compreende uma área de 966,835715 hectares. Sendo assim, para o consumo atual desta variável, de modo que seja respeitada a capacidade de regeneração do ecossistema, o município de Caicó necessita apresentar uma área bioprodutiva equivalente ou superior a área encontrada pelo cálculo da Pegada Ecológica total da população (gha). Caso contrário, significa dizer que o município de estudo apresenta um déficit ecológico, como também pode ser considerado insustentável.

Entende-se como área bioprodutiva os espaços biologicamente produtivos que protegem a biodiversidade. Segundo Jara (2007), esses espaços podem ser classificados como espaço de cultivo, mares, florestas, áreas construídas e pastagens. De modo que, juntos devem ser igual ou superior a área da pegada ecológica total de um determinado local, não apenas em relação a uma variável como proposto no nosso estudo, e sim a todas as variáveis necessárias.

Percebendo a relevância da variável em questão, diante da sua escassez em relação a sua potabilidade, e tomando por base a caracterização climática do município, faz-se necessário que políticas de conscientização sejam criadas, com o objetivo de levar informações acerca dos efeitos oriundos do desperdício desse recurso natural, em prol de um equilíbrio entre homem e natureza.

Pensando nisso e avaliando o consumo indiscriminado de água na região, mesmo havendo uma certa consciência da população de sua escassez, propõe-se como método para reduzir esse déficit, a organização da prefeitura junto as escolas da região para instalação da educação ambiental na grade curricular do alunos de ensino básico e fundamental. De modo a conscientizar as crianças e adolescentes da necessidade de reduzir os desperdícios.

Além disso, através de pesquisa exploratória, percebeu-se insignificantes movimentos de conscientização popular como palestras, cursos, áreas de preservação e até mesmo de coleta seletiva. Propõe-se então, uma melhoria na prefeitura a fim de dar ênfase a essa preocupação.

\section{CONSIDERAÇÕES FINAIS}

Como foi anteriormente exposto, a pesquisa é pressuposto para a consecução do projeto de pesquisa do PIBITI engajado pelo CNPq, tendo sido iniciado em agosto do presente ano e, conforme cronograma, estando no terceiro mês, iniciando-se a coleta de dados. Assim, passados os levantamentos bibliográficos, a pesquisa volta-se para a apreciação de dados e, estando ainda no seu início e revelando-se ainda mais complexo e árduo, não foi possível coletar os dados da área bioprodutiva da região e assim identificar o grau de sustentabilidade do município como era o objetivo original.

Entretanto, compreende-se que o cálculo da Pegada Ecológica junto com a caracterização do objeto de estudo, já deixa margem para atestar a difícil situação cometida pelo município de forma a demonstrar fundamentação suficiente para sugerir soluções secundárias para a região.

Como aqui revelado, a área necessária para o consumo atual de água é de 966,835715 hectares de terra. Uma vez que, essa Pegada Ecológica da população é a área total de terra requerida para produzir a água consumida. Apesar do cálculo não prever o futuro, entende-se que com o passar dos anos, com o aumento do consumo e com aumento do contingente 
populacional, os impactos ocasionados pela utilização dos recursos aumentarão, caso não sejam respeitados os limites da capacidade de regeneração do sistema natural. Sendo ainda uma suposição positiva já que se garante que durante os anos não haverá mais destruições, desmatamentos, erosões, plantações, entre outras coisas, que na prática, é insustentável.

De fato, para sustentar a população caicoense, foram emitidos 705,7195 toneladas de gás carbônico para os $1.907 .350 \mathrm{~m}^{3}$ de água consumida, contribuindo efetivamente para o aquecimento global. Segundo o Instituto Nacional de Pesquisas Nacionais, as temperaturas da região Nordeste do Brasil ira variar de $2^{\circ}$ a $4^{\circ}$. Assim ocorrendo, a sensação térmica da região objeto do nosso estudo será praticamente insuportável. As consequiências dessas emissões são muitas, destaca-se, para região, o aumento de queimadas e ondas de calor.

Entretanto, através da pesquisa, percebe-se que a região ainda é privilegiada quando comparadas a países como Argélia, Israel, Jordânia, entre outros. Dias (2006) enfatiza que a disponibilidade desses países é de menos de $1.000 \mathrm{~m}^{3}$ de água por pessoa ao ano, caracterizando uma escassez crônica da água. Dividindo a disponibilidade hídrica estimada da região segundo dados da Universidade Federal do Rio Grande do Norte - UFRN (400.500 m³) pela população disponibilizada pelo Censo 2010 do IBGE (62.727 hab), obtemos um resultado superior de $6.467 \mathrm{~m}^{3}$ de água por pessoa ao ano.

Porém, sabe-se que os resultados aqui obtidos ainda são positivos, uma vez que os dados aqui mencionados são estimativas de consumo e, portanto, o resultado aproxima-se o máximo possível da realidade. Observa-se que a Pegada Ecológica dimensionada foi representada por hectares globais, isso, como foi dito, contribui para os estudos mundiais e tornam possíveis ações que possam reduzir as conseqüências desse estudo. A produtividade, nesse caso, é dada obtendo-se o potencial de alcançar a produção agrícola máxima a um nível específico de entradas.

E, entendendo esse pressuposto de que a Pegada Ecológica aproxima-se da realidade, enfatiza-se que ela é subavaliada em função da complexidade do ecometabolismo urbano, sendo difícil considerar todos os subsistemas existentes. Portanto, conclui-se que o socioecossistema urbano estudado, emite gases-estufa para a atmosfera produzindo direta ou indiretamente alterações no uso do solo e contribuindo para alterações climáticas brandas.

Nessa perspectiva, espera-se que o estudo em sua relevância possa contribuir com o desenvolvimento do município de Caicó. Contudo, diante da utilização desenfreada dos recursos naturais e da necessidade, cada vez maior, do ambiente de recuperação, pensa-se erroneamente, que nada mais se pode fazer. Pelo contrário, é a partir de estudos de pequenas dimensões, de erros cometidos, e mudanças nos comportamentos humanos que transformações positivas podem ocorrer no ambiente em um todo. Assim sendo, considera-se que a Pegada Ecológica do consumo de água do município em questão possa modificar costumes, bem como revelar o valor real da água para a vida na Terra.

\section{REFERÊNCIAS}

1. Agência Nacional de Águas. Cadernos de recursos hídricos: Disponibilidade e demandas de recursos hídricos no Brasil. Brasília - DF, 2005.

2. AlVES, G. S.; MEDEIROS, A. J. A desertificação no Rio Grande do Norte: uma agonia crescente. In: SOUZA, F. das C. S. (org). Potencialidades e (in)sustentabilidade no semi-árido potiguar. Natal: Editora do CEFET-RN, 2005. 
3. AMATA. Inteligência da floresta viva. Serviços ambientais - Carbono. São Paulo, 2008. $11 \mathrm{p}$

4. ARAUJO, G. H. de S.; ALMEIDA, J. R. de; GUERRA, A. J. T. Gestão ambiental de áreas degradadas. Rio de Janeiro: Bertrand Brasil, 2005.

5. Associação Portuguesa dos Recusos Hídricos (APRH). Águas subterrâneas. Disponível em: < www.aprh.pt/pdf/triptico_CEAS.pdf > Acesso em 20 Nov. 2010.

6. BELLEN, H. M. V. Indicadores de Sustentabilidade: uma análise comparativa. Rio de Janeiro: Editora FGV, 2008.

7. BRASIL. Ministério de Minas e Energia. Projeto cadastro de fontes de abastecimento por água subterrânea Estado do Rio Grande do Norte: Diagnóstico do Município de Caicó. Recife: CPRM/PRODEEM, 2005. 29 p.

8. BRASIL. Secretaria de Planejamento e Finanças. Plano de desenvolvimento sustentável do Seridó. Caicó - RN, 2000. 316 p.

9. CHAMBERS, N.; SIMMONS, C.; WACKERNAGEL, M. Sharing nature's interest: ecological footprint as an indicator of sustainability. London: Earthscan Publications Ltd., 2000.

10. COMISSÃO MUNDIAL DE MEIO AMBIENTE E DESENVOLVIMENTO (CMMD). Relatório nosso futuro comum. 2. ed. Rio de Janeiro: FGV, 1991.

11. CREA-MG. Agenda 21. Belo Horizonte, 2004.

12. DIAS, G. F. Pegada ecológica e sustentabilidade humana. São Paulo: Gaia, 2006.

13. INSTITUTO BRASILEIRO DE GEOGRAFIA E ESTATÍSTICA - IBGE. Rio Grande do Norte. $2009 . \quad$ Datal, em: <http://www.ibge.gov.br/cidadesat/topwindow.htm?1 > Acesso em 02 Dez. 2010.

14. JARA, R. B. S., Avaliação ecológica-termodinâmica e econômica de nações: o peru como estudo de caso. Tese de doutorado: Campinas,2007.

15. LEITE, A. M. F.; VIANA, M. O. de L. Pegada ecológica: instrumento de análise do metabolismo do socioecossistema urbano. In: VEIGA, J. E. da (org). Economia socioambiental. São Paulo: Editora Senac São Paulo, 2009.

16. LISBOA, C. K.; BARROS, M. V. F. A pegada ecológica como instrumento de avaliação ambiental para a cidade de Londrina. Confins, n.8, 2010. Disponível em: < http://confins.revues.org/index6395.html>. Acesso em: 28 ago. 2010.

17. MALVEZZI, Roberto. Semi-árido: uma visão holística. Brasília. Confea, 2007. 920 p.

18. MINISTÉRIO DO MEIO AMBIENTE (MMA). Departamento de articulação institucional e Agenda 21. Agenda 21 local: exemplos e andamentos no Brasil. Brasília, 2002.

19. O’MEARA, M. Explorando uma nova visão para as cidades. Estado do Mundo, 1999 p.138.

20. PAINEL INTERGOVERNAMENTAL SOBRE MUDANÇA DO CLIMA (PNUMA). 4. 2007, Suiça. Mudança do clima 2007: A base das ciências físicas. Paris, 2007.

21. PANORAMA dos usos de recursos hídricos na bacia hidrográfica do rio PiranhasAçu e o CBH Piranhas-açu. Patos/PB, 2009. Disponível em: <www.piranhasacu.cbh.gov.br/.../20091209_ApresentacaoPanoramaUsosRecursosHi dricos.pdf>Acesso em 25 Nov. 2010. 
22. PARENTE, A. Indicadores de sustentabilidade ambiental: um estudo do Ecological Footprint Method do município de Joinville - SC. 2007. 197 f. Dissertação (Mestrado em Administração)-Universidade do Vale de Itajaí, Santa Catarina, 2007.

23. PEREIRA, L. G. Síntese dos métodos de Pegada Ecológica e análise emergética para diagnóstico da sustentabilidade de países: $O$ Brasil como estudo de caso. 2008. 183 f. Tese - Universidade Estadual de Campinas. São Paulo, 2008.

24. SILVA, A. M. da; CORREIA, A. M. M.; CÂNDIDO, G. A. Ecological Footprint Method: Avaliação da sustentabilidade do município de João Pessoa - PB. In: CÂNDIDO, G. A. (Org.). Desenvolvimento sustentável e sistemas de indicadores de sustentabilidade. Campina Grande - PB: Ed. UFCG, 2010.

25. VALADÃO, C. E. A. et al. Classificação climática da Microrregião do Seridó/RN. Programa de Pós-Graduação em Ciências Climáticas. Natal. Disponível em: <www.cbmet2010.com/anais/artigos/584_23902.pdf > Acesso em 20 Nov. 2010.

26. VEIGA, J. E. da. Desenvolvimento sustentável: o desafio do século XXI. Rio de Janeiro: Garamond, 2008.

27. WACKERNAGEL, M.; REES, W. Our Ecological Footprint: reducing human impacto on the earth. Canadá: New Society Publishers, 1962. 